\title{
Virtual Analysis of Stresses in Human Teeth Restored with Esthetic Posts
}

\author{
Martha Vasconcellos Amarante ${ }^{\mathrm{a}}$, Marcos Venicius Soares Pereira ${ }^{\mathrm{b} *}$, \\ Fathi Aref Ibrahim Darwish ${ }^{c}$, Arnaldo Freitas Camarão ${ }^{\mathrm{d}}$ \\ a'Department of Dentistry, Salgado de Oliveira University, \\ Rua Marechal Deodoro, 211, Centro, 24020-420 Niterói - RJ, Brazil \\ ${ }^{\mathrm{b}}$ Department of Materials Science and Metallurgy, PUC-Rio \\ Rua Marquês de São Vicente, 225, Gávea, 22453-900 Rio de Janeiro - RJ, Brazil \\ 'Department of Civil Engineering, UFF \\ Rua Passo da Pátria, 156, São Domingos, 24210-240 Niterói - RJ, Brazil \\ ${ }^{\mathrm{d}}$ South America Engineering, Arvin Meritor of Brazil Automotive Systems \\ Av. João Batista, 825, Centro, 06097-105 Osasco - SP, Brazil
}

Received: July 20, 2008; Revised: October 14, 2008

\begin{abstract}
The use of intra-radicular posts for rebuilding of damaged teeth is a normal practice in contemporary dentistry. However, dental roots restored with posts are subjected to the risk of failure under occlusal loads, particularly in cases of small dentin thickness. This study adopted the finite element analysis to compare the elastic stress distribution in simulated endodontically treated maxillary central incisor restored with two different esthetic posts, a ceramic post and a prefabricated fiber glass post. Under masticatory load, the shear stress and von Mises equivalent stress were determined for the different regions of the two models. The results demonstrated that stress concentrations occurred mainly in the cervical dentin in the prefabricated fiber glass post model. The ceramic post model presented stress concentration in a region limited to the proper post adjacent to its apical end, thus preserving the root dentin.
\end{abstract}

Keywords: ceramic post, fiber glass post, shear stresses, von Mises equivalent stresses

\section{Introduction}

Contemporary restorative dentistry has the main purpose of rehabilitating the function and esthetic of teeth which had their structure severely degraded due to caries or fracture. Restoration of endodontically treated teeth, with large portion of their coronal dentin already damaged, is commonly achieved by installing a post in the root cavity in order to provide a base for continuing the reconstruction process and to secure the retention of the restored tooth structure. Although some studies ${ }^{1}$ indicate that intra-radicular posts reinforce pulpless teeth, recent investigation $\mathrm{s}^{2-6}$ have demonstrated that root post transmit masticatory loads to the tooth root and supporting structures. Accordingly, research works ${ }^{7-13}$ related to the biomechanics of dental materials have been carried out to evaluate the effect of masticatory loads on the stress distribution within endodontically treated teeth restored with intra-radicular posts. This allows one to pinpoint highly stressed regions where fracture is expected to initiate.

The structural integrity and clinical longevity of post-and-core restored teeth are therefore strongly dependent on the state of stress created in their different regions due to occlusal loads. In addition to the magnitude and direction of such loads, the stress state at a given point within a restored tooth is also influenced by factors like the design and material of the post and the quantity and quality of the remaining root tissue ${ }^{14-19}$. As the extensive loss of root dentin increases the risk of radicular fracture, appropriate mechanical behavior of the post is considered, in this case, to be fundamental to the success of rehabilitating restored teeth ${ }^{20}$.

Numerous methods are available for post-and-core build-up, but the most widely used can be classified into two basic types, namely direct and indirect techniques. The direct technique involves the use of a commercial prefabricated post adapted into the root canal which is then filled with composite resin. This technique offers the advantage of requiring few preparatory sessions, thus reducing clinical procedure expenditure. Fiber glass and fiber carbon are the post materials most utilized for this type of restoration. The indirect technique, on the other hand, requires a pattern taken from the prepared root cavity to fabricate a cast post which conforms to the morphology of the prepared root canal. Cast posts are usually made of metallic alloys and are frequently indicated for teeth which, following endodontic treatment, end up with little remaining structure and/or large canal space. More recently, however, a technique for preparing ceramic posts has been developed ${ }^{21,22}$, with the purpose of conferring good esthetic features and securing perfect fitting in the root canal.

The finite element method (FEM) has been used for stress and strain analysis in dental biomechanics for nearly four decades ${ }^{23-25}$. The method adopts a mathematical model which corresponds to the geometry of the structural component to be analyzed and then attempts to simplify the calculations by the complete subdivision of the model in small elements, resulting in a mesh where the mechanical properties of the material and applied loads to the component are taken into account. The subdivision of the structure allows one to determine the stress distribution and hence to identify highly stressed regions where cracks are most likely to nucleate and, eventually, lead to partial or total fracture of the restored tooth. Despite the advantages of the finite element method, it should be emphasized that the use of improper data concerning material's properties, model geometries or boundary conditions would result in deficient or even incorrect outputs? ${ }^{7}$. 
The present study has the purpose of applying the finite element method to determine the stress distribution in a maxillary central incisor, with a small root-dentin thickness, restored with two different esthetic posts, namely a ceramic post (indirect technique) and a prefabricated fiber glass post with composite resin (direct method of fabrication). The results obtained with the posts are to be compared to one another, focusing the regions of stress concentration, where cracks can nucleate and eventually propagate leading to the loss of structural integrity and finally ultimate fracture of the restored tooth.

\section{Numerical Procedure}

Two two-dimensional models of a maxillary central incisor, $21 \mathrm{~mm}$ in length, were created by the software AutoCAD 2000 using Wheeler's data ${ }^{26}$. These models are presented in Figures 1 and 2 in a vestibular-lingual cross section and both of them include the supporting structures, namely periodontal ligament $(0.175 \mathrm{~mm})$, cortical bone $(0.5 \mathrm{~mm})$ and sponge bone. The cement layer that surrounds the root is considered to have the same elastic properties as those of the tooth dentin (and hence cement and dentin in this study are admitted to be one and the same material). The average thickness of the root dentin was taken as $1 \mathrm{~mm}$, thus simulating a weakened root, frequently encountered in real clinical cases.

The model presented in Figure 1, denominated Model 1, represents a pulpless tooth, with $4 \mathrm{~mm}$ of remaining gutta-percha apical seal, restored with a zirconia post according to the indirect technique. It is worth mentioning that this type of post is utilized in virtue of its high rigidity associated with excellent esthetic features ${ }^{22,27,28}$. Fracture in this type of post usually originates at microscopic manufacturing defects which can cause crack nucleation and propagation ${ }^{11,21,29}$.

Figure 2 presents the second model, denominated Model 2, representing the same tooth structure described in Model 1, but now with a prefabricated cylindrical post of fiber glass, $12 \mathrm{~mm}$ long and $1.8 \mathrm{~mm}$ wide, centered in the root cavity and filled with composite resin. The main advantages of fiber glass posts are related to their biocompatibility and to the similarity of their elastic modulus to that of the tooth dentin ${ }^{30}$. A common feature of the two models refers to the fact that an all ceramic crown is placed in the coronal portion of both models.

The program used for the stress calculations was ANSYS 9.0 (Swanson Analysis Systems, Inc., Houston, Penn.). All materials used in the simulation were assumed to be homogeneous, isotropic and linear elastic and their elastic properties (elastic modulus and Poisson's ratio) are presented in Table 1.

Model 1 and Model 2 were meshed respectively in 11,274 and 11,099 quadratic elements with 11,455 and 11,278 nodes. All nodes on the bone surface below the apex were constrained to avoid their movement in the $\mathrm{X}$ (horizontal) and $\mathrm{Y}$ (vertical) directions. In order to simulate masticatory loading, a $100 \mathrm{~N}$ force was considered to be uniformly distributed along an $8 \mathrm{~mm}$ span and oriented diagonally at an angle of $45^{\circ}$ with respect to the longitudinal axis of the tooth, as indicated in Figures 1 and 2.

Applying the finite element method to the meshed models for the given boundary and loading conditions, the stress distribution can be evaluated and a comparison between the two models can be visualized.

\section{Results}

The results obtained with the finite element method are presented in terms of the maximum in-plane shear stress and von Mises equivalent stress, developed in the different regions of the two models in question. Considering Model 1, the shear stress distribution and the von Mises equivalent stresses are presented in Figures 3 and 4, respectively.

Table 1. Elastic properties of the materials involved in the FEM calculation'.

\begin{tabular}{lcc}
\hline \multicolumn{1}{c}{ Material } & $\begin{array}{c}\text { Elastic modulus } \\
(\mathrm{MPa})\end{array}$ & $\begin{array}{c}\text { Poisson's } \\
\text { ratio }\end{array}$ \\
\hline Dentin & $18.6 \times 10^{3}$ & 0.31 \\
Periodontal Ligament & 69 & 0.45 \\
Cortical Bone & $13.7 \times 10^{3}$ & 0.30 \\
Sponge Bone & $1.37 \times 10^{3}$ & 0.30 \\
Gutta-Percha & 0.69 & 0.45 \\
Zirconia Post & $150 \times 10^{3}$ & 0.25 \\
Fiber Glass Post & $40 \times 10^{3}$ & 0.32 \\
Composite Resin & $22.2 \times 10^{3}$ & 0.28 \\
Ceramic Crown & $96 \times 10^{3}$ & 0.26 \\
\hline
\end{tabular}

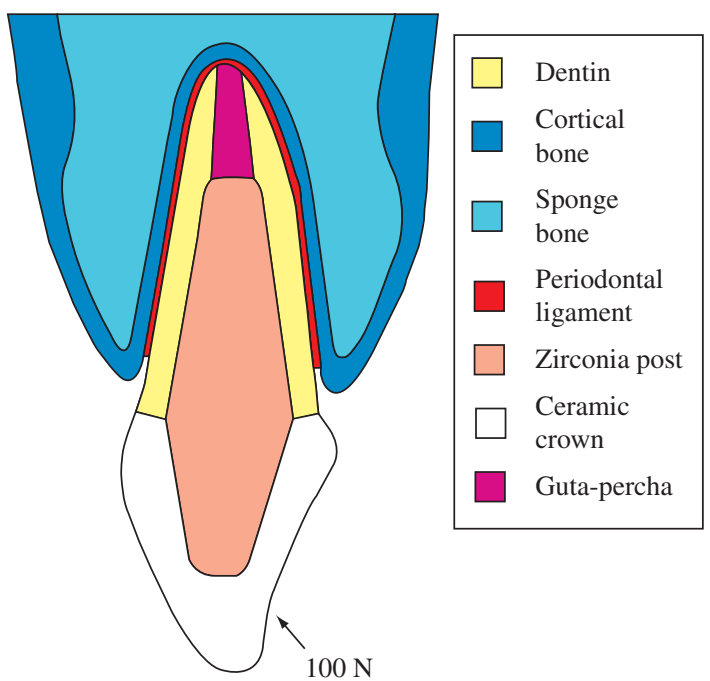

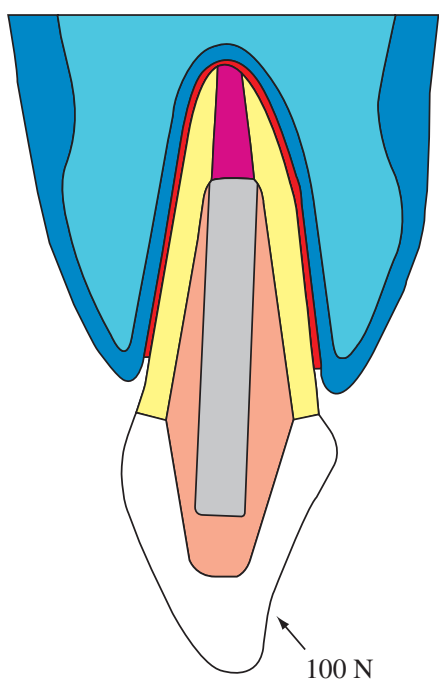

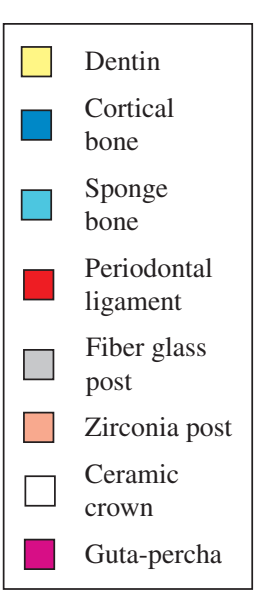

$100 \mathrm{~N}$

Figure 1. Zirconia post restored model.

Figure 2. Fiber glass post restored model. 


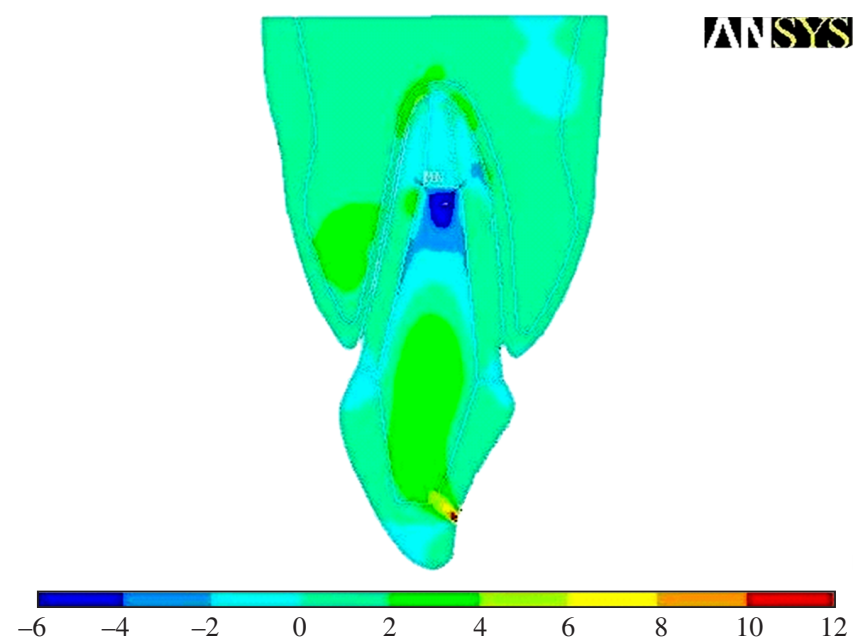

Figure 3. Shear stress (MPa) distribution in Model 1.

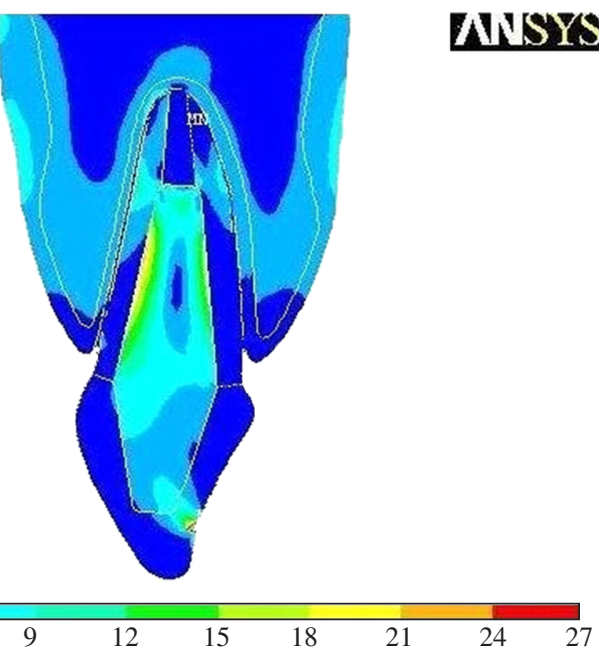

Figure 4. Von Mises equivalent stresses (MPa) in Model 1.

For Model 2, Figure 5 is representative of the shear stress distribution, while Figure 6 is indicative of the von Mises equivalent stresses.

The importance of evaluating shear stresses in dentistry is mainly related to the fact that excessively high stress levels may lead to loss of adhesion at the interface of different materials with the consequent loss of structural integrity and eventually fracture of the restored tooth. The von Mises equivalent stress combines normal and shear stresses, acting at a given point, in a resultant normal stress, which, on achieving high levels can cause fracture due to the brittle nature of tooth tissues.

As can be observed from Figure 3, the ceramic-post restored incisor (simulated by Model 1) presented under loading shear stress concentration in the middle of the post close to the tooth cervical region. Smaller regions of highly concentrated shear stress were found to be present at the apex of the post near the endodontic gutta-percha filling and on both sides of the dentin.

In regard to the von Mises equivalent stress, Figure 4 indicates that the highest levels of this stress under loading are achieved in the inner post within the middle third of the tooth. However, as can be seen from this figure, the equivalent stress exhibits higher levels on the vestibular side opposite to the side where the load is applied to

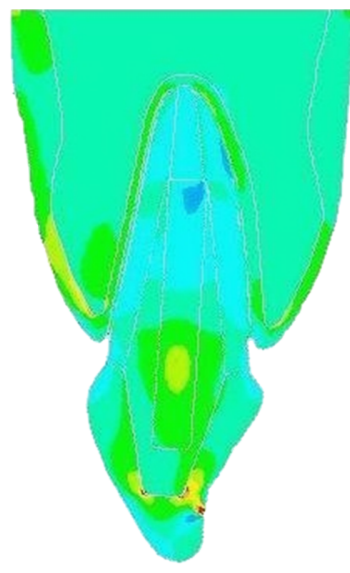

MNSTYS

$\begin{array}{lllllllll}-4.5 & -3 & -1.5 & 0 & 1.5 & 3 & 4.5 & 6 & 7.5\end{array}$

Figure 5. Shear stress (MPa) distribution in Model 2.
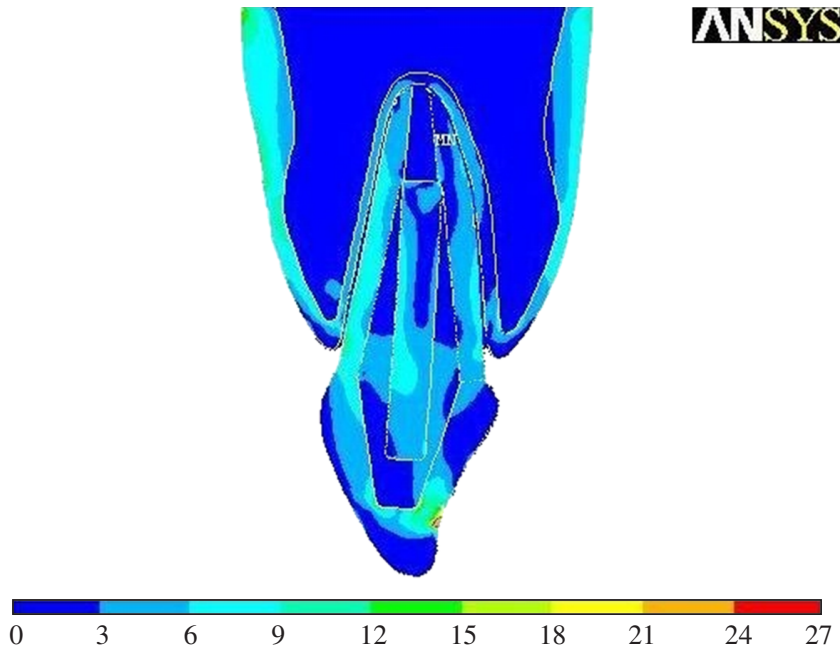

Figure 6. Von Mises equivalent stresses (MPa) in Model 2.

the tooth. Considerable von Mises stress values were also observed, mainly on the vestibular side, in the root dentin adjacent to the apical extremity of the post.

As to the fiber glass-resin restored tooth (Model 2), Figure 5 indicates that the shear stress is concentrated both in the middle of the fiber glass post close to the cervical region of the tooth and at the end of the post. The von Mises equivalent stress (Figure 6), on the other hand, achieves its highest level in the tooth dentin, mainly in the middle of cervical regions on the vestibular side of the tooth.

\section{Discussion}

The ability of the intra-radicular post, placed in substitution of lost tooth tissue, to support coronal restoration under occlusal loads is a critical factor for the success of this type of dental treatment. This is borne out by the fact that failure of the post leads, almost invariably, to failure of the coronal restoration.

The FEM can play an important role in predicting the state of stress acting in the different regions of the restored tooth under masticatory loads. This, in turn, serves as a pertinent tool to pinpoint regions within the restored structure that are susceptible to fracture initiation and crack propagation, meaning failure of the restoration 
process. However, the success of applying the FEM requires appropriate choice of the models which have to be compatible with the boundary and loading conditions imposed on the structure. The structures modeled in this study can vary from one individual to another and the shear stress evaluation was carried out under static type loading. This imposes a limitation on the general applicability of the results despite their meaningful significance both qualitatively and quantitatively.

The results of the present study have revealed the absence of shear stress concentration at the post-dentin interface. One can therefore discard the possibility of failure, by displacement along this interface, under the masticatory load simulated in the study. The results, though, demonstrated that both models concentrated shear stress in the post, suggesting that failure of the restoration, if it occurs, can only take place by shearing of the proper post. According to the literature $3,10,16,18,19,25$, the stability of the post is related to its geometry. Conic or short posts, which did not achieve appropriate penetration into the root canal, have more probability of being extruded. Shear stress concentrations were also found to be present at core-crown interfaces, predisposing the structure to displacement of the crown during mastication. Adequate preparation of the core and the use of adhesive cementation can therefore contribute to minimizing the risk of such displacement.

Considering the results of von Mises equivalent stress distributions (Figures 4 and 6), one can may conclude that the use of less rigid post material, that is similar to dentin, results in a more uniform stress distribution in comparison with that associated with a more rigid post. However, the less rigid post was found to promote higher equivalent stress levels mainly in the cervical region of the tooth dentin. According to some authors ${ }^{2,19,23}$, the cervical third is the region which is more propense to fracture in teeth restored with intra-radicular post, particularly in those with reduced periodontal support. The results of the present study have shown that high level equivalent stress is present at the apical end of the post, suggesting that the geometry of the post in this extremity can contribute to the stress state acting there. Accordingly, acute angles should be avoided to prevent crack initiation and, consequently, radicular fracture. Further, the present study showed that the palatine side is submitted to higher normal stress levels, indicating that one may opt, during root preparation, for more wearing on the vestibular side.

Finally, it must be emphasized that failure in treatments involving post-and-core restorations are related to masticatory loads, restoration geometry and restoration materials. Occasionally, though, radicular fracture can occur even in well executed dental restorations. This is believed to be, essentially, related to lack of precise information regarding the forces that act on restored teeth during mastication. Precise definition of these forces followed by appropriate applications of the finite element method to predict the stress state at critical points within a restored tooth seems to be the path followed by research workers in the field of dental biomechanics.

\section{Concluding Remarks}

The present study had evaluated the stress distribution in a maxillary central incisor restored with two different esthetic posts (a ceramic and a prefabricated fiber glass) by means of a finite elements analysis. According to the results obtained in the numerical simulations, the following conclusions can be drawn:

- The restoration geometry and the elastic moduli of the materials involved in the process can influence the stress distribution pattern developed in the restored tooth under occlusal loads;

- The two models considered in this study presented stress concentration in the radicular dentin adjacent to the apical end of the post, indicating that this is a critical region in regard to the success of the restorative treatment;

- The model restored with prefabricated post showed more homogeneous stress distribution, but presented stress concentration in the dentin, mainly in the cervical region. On the other hand, the model restored with ceramic post presented stress concentration in the proper post, thus preserving the radicular dentin; and

- Finally, one may also conclude that, whereas ceramic posts placed according to the indirect technique, should be indicated for restorative treatments in case of weakened tooth roots, prefabricated posts are better suited for well conserved radicular structure.

\section{References}

1. Ko CC, Chu CS, Chung KH, Lee MC. Effect of posts on dentin stress distribution in pulpless teeth. The Journal of Prosthetic Dentistry. 1992; 68(3):421-427.

2. Reinhardt RA, Krejci RF, Pao YC, Srannard JG. Dentine stresses in post-reconstructed teeth with diminished bone support. Journal of Dental Research. 1983; 62(9):1002-1008.

3. Asmussen E, Peutzfeldt A, Sahafi A. Finite element analysis of stresses in endodontically treated, dowel-restored tooth. The Journal of Prosthetic Dentistry. 2005; 94(4):321-329.

4. Pierrisnard L, Bohin F, Renault P, Barquins M. Corono-radicular reconstruction of pulpless tooth: A mechanical study using finite element analysis. The Journal of Prosthetic Dentistry. 2002; 88(4):442-428.

5. Ho MH, Lee SY, Chen HH, Lee MC. Three-dimensional finite element analysis of the effects of posts on stress distribution in dentin. The Journal of Prosthetic Dentistry. 1994; 72(4):367-372.

6. Morgano SM. Restoration of pulpless teeth: application of traditional principles in present and future contexts. The Journal of Prosthetic Dentistry. 1996; 75(4):375-380.

7. Holmes DC, Diaz-Arnold AM, Leary JM. Influence of post dimension on stress distribution in dentin. The Journal of Prosthetic Dentistry. 1996; 75(2):140-147.

8. Yaman SD, Karacaer O, Sahin M. Stress distribution of post-core applications in maxillary central incisors. Journal of Biomaterials Applications. 2004; 18:163-177.

9. Holmgren EP, Mante FK, Shokoufeh E, Afsharzand Z. Stress in post and core build-up materials. Journal of Dental Research. 1999; 78(2):222-228.

10. Akkayan B, Dent M, Gulmez T. Resistance to fracture of endodontically treated teeth restored with different post systems. The Journal of Prosthetic Dentistry. 2002; 87(4):431-437.

11. Asmussen E, Peutzfeldt A, Heitmann T. Stiffness, elastic limit, and strength of newer types of endodontic posts. Journal of Dentistry. 1999; 27(4):275-278.

12. Catovic A, Seifert D, Guberina RP, Kvasnicka B. Influence of biomechanical factors on restoration of desvitalized teeth. Acta Stomatologica Croatica. 2000; 34(1):67-72.

13. Sadegui M. A comparison of the fracture resistance of endodontically treated teeth using three different post systems. Journal of Dentistry 2006; 3(2):69-76.

14. Fernandes AS, Shetty S, Coutinho I. Factors determining post selection: A literature review. The Journal of Prosthetic Dentistry. 2003; 90(6):556-562.

15. Ricketts DNJ, Tait CME, Higgins AJ. Post and core systems, refinements to tooth preparation and cementation. British Dental Journal. 2005; 198(9):533-541.

16. Assif D, Bitenski A, Pilo R, Oren E. Effect of post design on resistence to fracture of endodontically treated teeth with complete crowns. The Journal of Prosthetic Dentistry. 1993; 69(1):36-40. 
17. Lambjerg-Hansen $\mathrm{H}$, Asmussen E. Mechanical properties of endodontic posts. Journal of Oral Rehabilitation. 1997; 24(12): 882-887.

18. Yang HS, Lang LA, Molina A, Felton DA. The effect of dowel design and load direction on dowel-and-core restorations. The Journal of Prosthetic Dentistry. 2001; 85(6):558-567.

19. Fernandes AS, Dessai GS. Factors affecting the fracture resistence of post-core reconstructed teeth: a review. International Journal of Prosthodontics. 2001; 14(4):355-363.

20. Pidaparti RM, Beatty MW. Fracture toughness determination of dental materials by laboratory testing and finite elements models. Journal of Biomedical Materials Research. 1995; 29(3):309-314.

21. Cardoso RJA, Gonçalves EAN. Odontologia estética. $1^{\text {th }}$ ed. São Paulo: Artes Médicas Ltda.; 2002.

22. Meyenberg KH, Luthy H, Scharer P. Zirconium post. A new all-ceramic concept for nonvital abutment teeth. Journal of Esthetic and Restorative Dentistry. 1995; 7(2):73-80.
23. Vree JHP, Peters MCRB, Plasschaert AJM. A comparison of photoelastic and finite element analysis in restored tooth structures. Journal of Oral Rehabilitation. 1983; 10(6):505-517.

24. Zienkiewicz OC. The Finite Element Method in engineering science. $4^{\text {th }}$ ed. New York: McGraw-Hill; 1989.

25. Cook RD, Malkus DS, Plesha ME, Witt RJ. Concepts and applications of finite elements analysis. $4^{\text {th }}$ ed. New York: John Wiley \& Sons; 2002.

26. Wheeler RC. An Atlas of Tooth Form. $3^{\text {th }}$ ed. Philadelphia: W.B. Saunders Company; 1984.

27. Seymore KG. Stresses within porcelain veneers and the composite lute using diferent preparation designs. Journal of Prosthodontics. 2001; 10(1):16-21.

28. Hochman N, Zalkind M. New all-ceramic indirect post-and-core system. The Journal of Prosthetic Dentistry. 1999; 81(5):625-629.

29. Fischer H, Rentzsch W, Marx R. Elimination of low-quality ceramic posts by proof testing. Dental Materials. 2002; 18(8):570-575.

30. Newman MP, Yaman P, Dennison J. Fracture resistance of endodontically treated teeth restored with composite posts. The Journal of Prosthetic Dentistry. 2003; 89(4):360-367. 